\title{
Persuasive Interventions for Controversial Cancer Screening Recommendations: Testing a Novel Approach to Help Patients Make Evidence-Based Decisions
}

\author{
Barry G. Saver, $M D, M P H^{1-3}$ \\ Katbleen M. Mazor, EdD ${ }^{1,2}$ \\ Roger Luckmann, MD, MPH \\ Sarab L. Cutrona, MD, MPH $H^{1,2,4}$ \\ Marcela Hayes, BS, BA ${ }^{1}$ \\ Tatyana Gorodetsky, MEd (ed $)^{5}$ \\ Nancy Esparza, MEd \\ Gonzalo Bacigalupe, EdD, $M P H^{6}$ \\ 'University of Massachusetts Medical \\ School, Worcester, Massachusetts
}

${ }^{2}$ Meyers Primary Care Research Institute,

Worcester, Massachusetts

${ }^{3}$ Swedish Family Medicine Residency

Cherry Hill, Seattle, Washington

${ }^{4}$ Veterans Health Administration, HSRD COIN Edith Nourse Rogers Memorial Hospitalo, Bedford, Massachusetts

${ }^{5}$ Center for Health Impact, Worcester, Massachusetts

${ }^{6}$ University of Massachusetts, Boston, Massachusetts

Conflicts of interest: authors report none.

\section{CORRESPONDING AUTHOR:}

Barry G. Saver, MD, MPH

Swedish Family Medicine Residency

Cherry Hill

$55016^{\text {th }}$ Ave, Suite 400

Seattle, WA 98105

Barry.Saver@swedish.org

\begin{abstract}
PURPOSE We wanted to evaluate novel decision aids designed to help patients trust and accept the controversial, evidence-based, US Preventive Services Task Force recommendations about prostate cancer screening (from 2012) and mammography screening for women aged 40 to 49 years (from 2009).

METHODS We created recorded vignettes of physician-patient discussions about prostate cancer screening and mammography, accompanied by illustrative slides, based on principles derived from preceding qualitative work and behavioral science literature. We conducted a randomized crossover study with repeated measures with 27 men aged 50 to 74 years and 35 women aged 40 to 49 years. All participants saw a video intervention and a more traditional, paper-based decision aid intervention in random order. At entry and after seeing each intervention, they were surveyed about screening intentions, perceptions of benefits and harm, and decisional conflict.
\end{abstract}

RESULTS Changes in screening intentions were analyzed without regard to order of intervention after an initial analyses showed no evidence of an order effect. At baseline, $69 \%$ of men and $86 \%$ of women reported wanting screening, with $31 \%$ and $6 \%$, respectively, unsure. Mean change on a 3-point, yes, unsure, no scale was $-0.93(P=<.001)$ for men and $-0.50(P=<.001)$ for women after seeing the video interventions vs 0.0 and $-0.06(P=.75)$ after seeing the print interventions. At the study end, $33 \%$ of men and $49 \%$ of women wanted screening, and $11 \%$ and $20 \%$, respectively, were unsure.

CONCLUSIONS Our novel, persuasive video interventions significantly changed the screening intentions of substantial proportions of viewers. Our approach needs further testing but may provide a model for helping patients to consider and accept evidence-based, counterintuitive recommendations.

Ann Fam Med 2017;15:48-55. https://doi.org/10.1370/afm.1996.

\section{INTRODUCTION}

$\mathrm{P}$ atients face many medical decisions, and rarely is the evidence about the balance of benefits and harms so unequivocal that it can be assumed all patients would make the same choice if adequately informed. Evidence can be complicated and incomplete, and experts' recommendations may conflict. Even when there is an evidence-based recommendation for a specific medical decision, patients' values might lead to a different choice. Patients are exposed to social norms, media campaigns, and powerful anecdotes regarding testing. ${ }^{1,2}$ Furthermore, human decision making rarely fits the idealized model of a rational, informed process. ${ }^{3,4}$ Order of presentation, loss- vs gain-based framing, anchor effects, and perceived norms can introduce biases, ${ }^{5-10}$ and adding information can make decisions more difficult. ${ }^{11-14}$ Shortcuts (heuristics) used to simplify decisions often lead to suboptimal choices. ${ }^{15,16}$

Thus, the ideal of the informed decision is difficult to achieve in practice. Charles et al note, "Patient preferences for information do not neces- 
sarily translate into information seeking behavior ${ }_{i}$ nor do patients who express preferences for some form of shared decision making necessarily act on these in the medical encounter."17 Patients who may not have clearly defined values or preferences when asked to make a decision may, instead, construct a preference to justify their choice. ${ }^{18}$ A Cochrane review of decision aids for treatment and screening decisions concluded there was high-quality evidence that decision aids could improve knowledge and reduce decisional conflict, moderate-quality evidence for helping people be more active in making decisions and improving risk perception, and low-quality evidence that decision aids led to decisions more congruent with patients' values. ${ }^{19}$

For preventive services, the focus has been more on promoting uptake; for cancer screening tests, the typical view is that more is better ${ }^{20,21}$ given the paradigm of early detection increasing chances for a cure. Few patients understand that some screening tests may reduce mortality only modestly or can result in harm. ${ }^{22}$ Little research has focused on helping clinicians and patients overcome their biases as they present information about screening benefits, harms, and uncertainties and attempt to make informed and/or shared decisions. ${ }^{23}$

The United States Preventive Services Task Force's (USPSTF) recommendation that women aged 40 to 49 years should make preference-based, individual decisions about mammography highlights the need for the development of effective, evidence-based approaches to help patients understand why seemingly counterintuitive recommendations might make sense. ${ }^{24,25}$ The USPSTF recommendation against screening for prostate cancer with the prostate specific antigen (PSA) tes $\mathrm{t}^{26}$ provides further impetus for such approaches.

Americans receive substantial amounts of low-value medical care. ${ }^{27-33}$ When recommending against care can evoke fear and distrust, clinicians are challenged to explain why a test or treatment might not be beneficial, a challenge compounded by advocacy groups mounting campaigns based on strong, emotional messages rather than unbiased evidence.

Some authors have suggested that advocacy should be combined with unbiased information, sometimes described as informed advocacy ${ }^{34}$ and beneficent persuasion. ${ }^{35}$ Swindell et al argue that autonomy is not what patients value most in their medical decision making, nor do most medical decisions resemble the model of an informed, autonomous choice. ${ }^{36}$ Typical medical practice more closely resembles an advocacy-based process than informed, shared decision making. Patients often receive recommendations about preference-sensitive choices with little or no discussion, and information is presented in an attempt to persuade only if they offer resistance. When strong, persuasive messaging is used to advocate for a specific choice, patients may need help understanding the rationale for making a considered decision.

In this article, we present the results of an initial evaluation of interventions developed to help patients consider and trust the 2009 USPSTF recommendations that women in their 40s should make an informed choice about mammography and the 2012 recommendation against prostate cancer screening.

\section{METHODS}

\section{Overview and Development of Interventions}

This study proceeded in 3 phases; phases 1 and 2 focused on intervention development, and phase 3 tested intervention effectiveness. This report focuses on phase 3, but begins with a brief overview of the first 2 phases to facilitate understanding of our approach and interventions.

Phase 1 involved the conduct and qualitative analyses of 6 focus groups ( 2 in English and 1 in Spanish with men aged 50 to 74 years discussing prostate cancer screening and the same with women aged 40 to 49 years discussing mammography). The focus groups were conducted to help us understand participants' attitudes toward the cancer screening tests we were addressing and factors that might lead patients to trust the USPSTF's recommendations. We concluded that (1) discussion needed to begin with information about the harms and limited efficacy of the tests because, without that information, considering not being screened did not make sense $e_{i}(2)$ participants were unaware of specific guidelines $s_{i}$ (3) discussion of guideline development processes and potential bias had no impact on participants' views ${ }_{i}(4)$ participants were not familiar with the USPSTF, and attempts to distinguish the USPSTF from other groups using bias-prone processes had no impact $_{i}(5)$ anecdotal experiences of family and friends with cancer screening, diagnosis, and treatment were powerful in shaping views about screening, even if the anecdotes were not about breast or prostate cancer screening; and (6) although no participant asked for evidence supporting cancer screening, many wanted to know there was good evidence supporting a recommendation to consider not being screened.

In phase 2, we developed sets of 3 videos of narrated slide presentations for each topic in both English and Spanish. One was framed as a conversation among friends, including a community health worker knowledgeable about the topic, 1 portrayed a physician-patient conversation, and the third was a presentation by an unseen narrator. The level of detail about the evidence varied in the presentations, being least in the first, and greatest in the last. We conducted 
6 additional focus groups, organized as in phase 1 , in which participants viewed the presentations in varying order and discussed their reactions to each. Other than 1 group of men disliking the friends' conversation format, there were no strong preferences for any particular format. Some participants stated that a physician-patient conversation seemed more convincing, and some stated that hearing the complex information more than once was helpful.

Based on these findings and the current literature on persuasion and behavior change, we then developed video presentations of slide shows, framed as physician-patient conversations (mammography, English, at https://youtu.be/6uGy72OCv_Q ${ }_{i}$ mammography, Spanish, at https://youtu.be/rs_pKyFo1DA; prostate cancer screening, English, at https://youtu.be/ v5z2Go4ZpO4, prostate cancer screening, Spanish, at https://youtu.be/nBce9xJo1lc). Overall flow and content are available in the Supplemental Figure, http://annfammed.org/content/15/1/48/suppl/DC1. Duration of the video presentations ranged from about $13 \frac{1}{2}$ minutes to almost 23 minutes, with Spanish-language and mammography presentations being longer.

\section{Comparator Interventions}

We sought unbiased, evidence-based comparators that were reasonably consistent with USPSTF recommendations and freely available for public use. For prostate cancer screening, we chose a composite of 2 paperbased decision aids developed by a multidisciplinary prostate cancer work group for the Massachusetts Department of Public Health for dissemination to primary care clinicians for use with men in Massachusetts. ${ }^{37,38}$ In a small pilot test, the decision aids were well received by patients and clinicians. For mammography, we used a paper-based Summary for Patients from the American College of Physicians that outlined the 2007 guidelines for mammography screening in women aged 40 to 49 years. ${ }^{39}$

\section{Participant Recruitment}

Men aged 50 to 74 years without a history of prostate cancer and women aged 40 to 49 years without a history of breast cancer who spoke English or Spanish were eligible to participate. We recruited a convenience sample using a broad outreach approach, including mailings to potentially eligible participants attending primary care clinics identified from hospital and community health center administrative data, signs placed in the academic medical center, outreach to persons who had indicated interest in participating in research studies to the UMass Center for Clinical and Translational Science, outreach to community contacts by study members from the Central Massachusetts
Area Health Education Center, and ads posted on Craigslist. Our goal was to recruit a sample with as much racial, ethnic, linguistic, and socioeconomic variation as possible with our available resources. Participants were informed they would be paid $\$ 40$ for up to 2 hours of their time. Interested eligible persons were scheduled to come in for a study visit with a bilingual community health worker.

\section{Conduct of Study Sessions}

All participants received both interventions. For the following reasons they were randomly assigned to see either our video intervention or the printed decision aid first: (1) comments in our phase 2 focus groups about the value of hearing the information more than once made us suspect we might see greater effects from multiple exposures; (2) as a formative study, we wanted to compare information from participants about the 2 types of interventions; and (3) we wanted to maximize the information we could obtain from each participant, knowing our resources were limited.

Study data were collected and managed using electronic data capture (REDCap) research tools ${ }^{40}$ hosted at the University of Massachusetts Medical School (UMMS). Randomization was carried out via REDCap with concealed allocation, stratified by sex and language spoken. Participants responded to survey questions in English or Spanish using a touchscreen tablet that directly entered the data into REDCap; a community health worker provided assistance as needed. After answering questions about demographics, family history, and experience with the screening test, participants were asked to indicate whether they wanted the test (yes, unsure, no), felt getting the test was right for them, and expected to discuss screening with their physician in the coming year (5-point Likert scales from "definitely yes" to "definitely no"). The low-literacy version of the Decisional Conflict Scale ${ }^{41,42}$ was used to measure 4 aspects of decisional conflict-uncertainty, feeling informed, clarity about personal values, and feeling supported in making the decision-with higher scores reflecting greater conflict. ${ }^{41}$ We also asked them their opinion on the balance of benefits and harms of the screening test (based on a 5-point Likert scale) and to indicate how much the women thought regular screening reduced a person's risk of dying of cancer (less than $25 \%, 25 \%$ to $49 \%, 50 \%$ to $75 \%$, more than $75 \%$, or absolutely no idea). Women were asked how often a woman should get mammograms once she started (every 1, 2, or 3 years, or not sure). Participants were then shown the intervention they had been randomized to see first and asked again to complete the Decisional Conflict Scale and the questions about their screening intentions and perceived benefits and harms. 
The community health worker offered to clarify any issues within their scope of training. Participants were shown the second intervention and asked to answer questions including those listed above.

This project was approved by the University of Massachusetts Medical School Institutional Review Board.

\section{Analyses}

Statistical analyses were conducted using SAS 9.2 (SAS Institute, Inc). Nonparametric tests were used to assess significance of responses to questions with yes, unsure, no and Likert-scale scores. Changes on the Decisional Conflict Scale responses were assessed using $t$ tests. We compared changes in screening attitudes and intentions after seeing each intervention, suspecting from previous feedback that attitudes might change progressively after seeing each intervention.

\section{RESULTS}

As shown in Table 1, 27 men and 35 women participated. Most were non-Hispanic white, and nearly 90\% had some education beyond high school. About one-fourth of women were Spanish-speaking Latinas, whereas only 1 man was a Spanish-speaking Latino.

As displayed in Figures 1 and 2, preferences for both prostate cancer screening and mammography changed significantly after viewing the video presentations but not after viewing the print (control) decision aid. For men, preferences changed primarily from wanting to not wanting screening, whereas for women the change was more balanced between being unsure

\section{Table 1. Participant Demographics}

\begin{tabular}{|c|c|c|}
\hline Characteristic & $\begin{array}{c}\text { Men } \\
(n=27)\end{array}$ & $\begin{array}{l}\text { Women } \\
(n=35)\end{array}$ \\
\hline Mean age, y & 58 & 46 \\
\hline \multicolumn{3}{|l|}{ Race, \% } \\
\hline White & 85 & 60 \\
\hline Black & 4 & 3 \\
\hline Asian & 0 & 6 \\
\hline Other, unknown ${ }^{a}$ & 11 & 31 \\
\hline Hispanic ethnicity, \% & 11 & 34 \\
\hline \multicolumn{3}{|l|}{ Education, \% } \\
\hline$\leq$ High school graduate & 12 & 11 \\
\hline Some college or college graduate & 35 & 49 \\
\hline$\geq 4$ Years of college & 54 & 40 \\
\hline $\begin{array}{l}\text { Previously screened for prostate/breast } \\
\text { cancer, \% }\end{array}$ & 46 & 91 \\
\hline $\begin{array}{l}\text { Previous abnormal prostate/breast cancer } \\
\text { screening result, \% }\end{array}$ & 11 & 37 \\
\hline Previous prostate/breast biopsy, \% & 4 & 9 \\
\hline
\end{tabular}

and not wanting screening. Because the order of the information given had no effect, we presented the analyses of changes after seeing each type of intervention, ignoring order. We found significant changes in participants' desire for both tests, feeling the test was right for them, and perceptions of the balance of benefits and harms. There was also a smaller, but statistically significant, change in men's perceptions of the balance of benefits and harms after viewing the print comparator (Table 2). Although our interventions were intended for shared decision making, we found they resulted in a significant decrease in men's intentions to discuss prostate cancer screening with their physicians; women's intentions trended in the same direction, though they were not significant at the $P<.05$ level.

Desired frequency of mammography screening also changed after seeing the interventions. At entry, $54 \%$ of women reported that women should get annual mammograms once they started, and 34\% indicated it should be biennial. This frequency changed to $14 \%$ annually and $60 \%$ biennially after viewing both interventions. Endorsement of biennial mammograms increased minimally (6\%) after seeing the paper decision aid and more (20\%) after our seeing our narrated video intervention, but this difference was not statistically significant.

Decisional Conflict Scale scores decreased substantially and progressively, and they were also not statistically significantly related to which intervention was received first. On a scale ranging from 0 (no conflict) to 100 (maximal conflict), scores for men decreased from a mean of 57 to 15 after seeing their first intervention and further decreased to a mean of 8 after seeing the second. For women, scores decreased from 32 to 18 to 13 , respectively.

\section{DISCUSSION}

Our interventions, designed to help viewers trust and accept the recommendations from the USPSTF on prostate cancer screening for men and screening mammography for women aged 40 to 49 years clearly influenced a number of participants to reconsider whether they wanted screening and changed the reported preferences of statistically significant proportions of our participants. This outcome is notably different from those reported for the use of many decision aids, including a recently published randomized controlled trial comparing 4 print formats for presenting information about 3 low-value screening tests, including the PSA test ${ }^{43}$; a recent evaluation of a decision aid for mammography for women in their forties that reported a significant decrease in decisional conflict, but no significant change in screening intentions ${ }^{44}$; and the 
Figure 1. Expressed preferences for prostate-specific antigen testing after seeing video, then paper, or vice versa (total $n=27$ men aged 50-74 years).

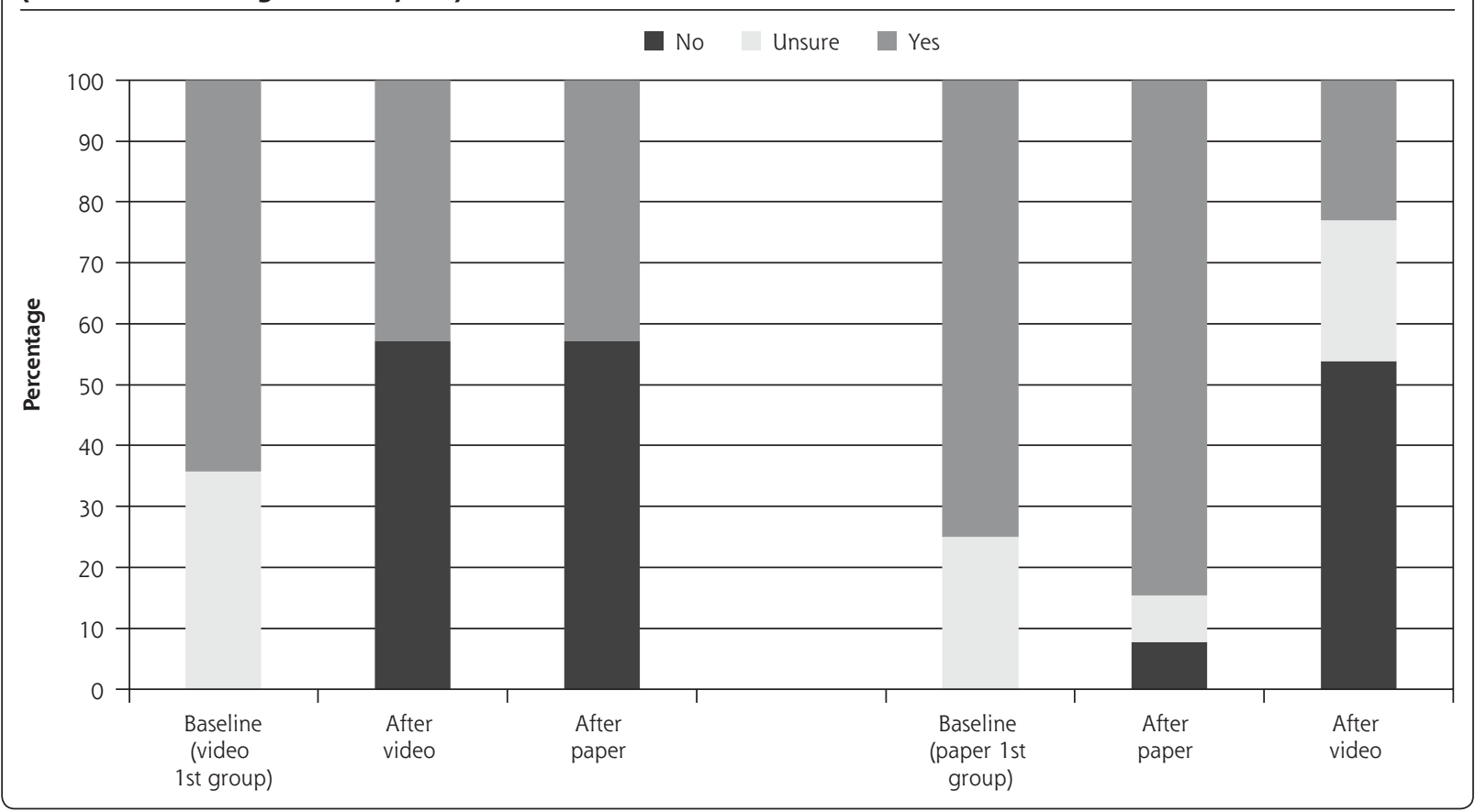

Figure 2. Expressed preferences for mammography testing after seeing video, then paper, or vice versa (total $\mathrm{n}=35$ women aged $40-49$ years).

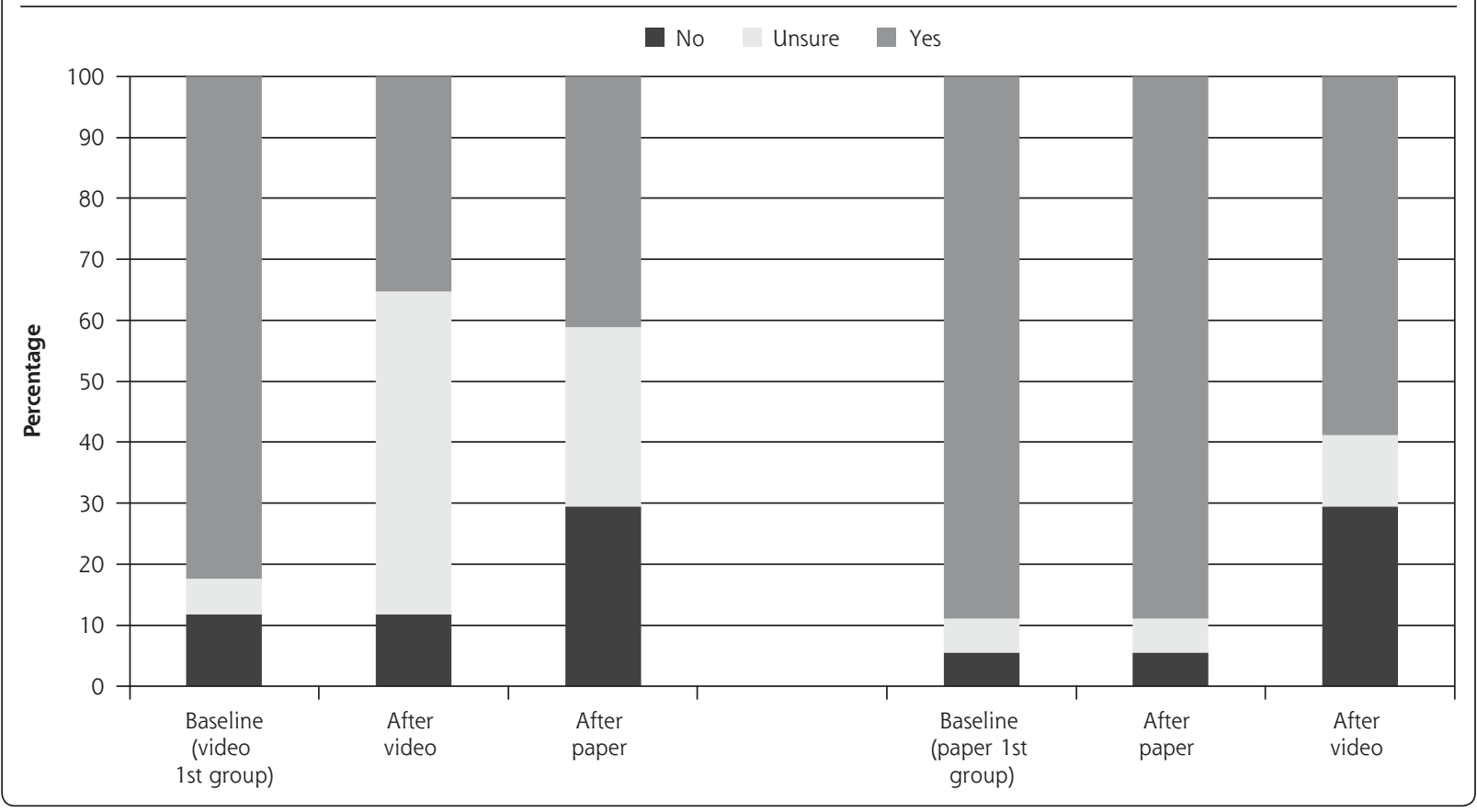

Cochrane review of decision aids, which found variable effects on choices, including mixed effects for PSA decision aids. ${ }^{19}$

We believe there are several reasons why, in our study, men were more likely than women to change from desiring to rejecting screening and women were more likely to end up uncertain. Major harms associated with prostate cancer screening (eg, impotence and incontinence) are easily understood and highly undesirable, whereas some harms associated with mammog- 
Table 2. Changes in Screening Attitudes Toward Cancer Screening

\begin{tabular}{|c|c|c|c|}
\hline Measure & $\begin{array}{c}\text { After Printed } \\
\text { (Control) Intervention } \\
\text { Mean Change } \\
(P \text { Value })^{\mathrm{a}}\end{array}$ & $\begin{array}{c}\text { After Video } \\
\text { Intervention } \\
\text { Mean Change } \\
(P \text { Value })^{\mathrm{a}}\end{array}$ & $\begin{array}{l}\text { Video vs Print } \\
\text { Difference } \\
\text { Mean Change } \\
{\text { (P Value })^{\mathrm{a}}}^{\text {( }}\end{array}$ \\
\hline \multicolumn{4}{|l|}{ PSA screening } \\
\hline Want PSA (yes $=2$, unsure $=1$, no $=0$ ) & $0.0(>.99)$ & $-0.93(<.001)$ & $-0.88(<.001)$ \\
\hline PSA right for $m e^{b}$ & $0.0(>.99)$ & $-1.6(<.001)$ & $-1.6(<.001)$ \\
\hline PSA harm-benefit balance ${ }^{b}$ & $-0.53(.01)$ & $-1.9(<.001)$ & $-1.3(.007)$ \\
\hline Intend to discuss PSA with physician' & $0.12(.38)$ & $-0.44(.03)$ & $-0.58(.003)$ \\
\hline \multicolumn{4}{|l|}{ Mammography screening } \\
\hline Want mammography (yes $=2$, unsure $=1$, no $=0$ ) & $-0.06(.75)$ & $-0.50(<.001)$ & $-0.44(.01)$ \\
\hline Mammography right for me $e^{b}$ & $0.06(.82)$ & $-0.77(<.001)$ & $-0.83(.002)$ \\
\hline Mammography harm-benefit balance ${ }^{b}$ & $-0.14(.38)$ & $-0.65(<.001)$ & $-0.50(.046)$ \\
\hline Intend to discuss mammography with physician b & $0.0(>.99)$ & $-0.29(.07)$ & $-0.29(.17)$ \\
\hline \multicolumn{4}{|l|}{ PSA = prostate-specific antigen. } \\
\hline \multicolumn{4}{|c|}{ Note: Interventions were presented to participants randomly. } \\
\hline \multicolumn{4}{|c|}{$\begin{array}{l}\text { a Wilcoxon signed rank tests used to assess significance. } \\
\text { b Score based on } 5 \text {-point Likert scale, where } 1=\text { definitely yes, to } 5=\text { definitely no. }\end{array}$} \\
\hline
\end{tabular}

raphy are less clear (eg, anxiety) or subtle and poorly understood (eg, overdiagnosis and overtreatment). Second, the evidence we presented indicated that prostate cancer screening might provide no benefit, saving 0 to 1 life per 1,000 men screened over 10 years, whereas mammography evidence indicated a modest mortality reduction of 1 life saved for every 2,000 women screened over 10 years. Third, our qualitative work found that women have been heavily socialized to value mammography, which was uncommon for PSA screening. Finally, the USPSTF recommendation is against prostate cancer screening; for mammography the recommendation is to make an informed choice, and women accepting the USPSTF's recommendation might appropriately end up being uncertain, with fewer expected to decide against screening.

In developing this project, given the generally limited effects of knowledge on behavior, we had expected to focus on crafting persuasive messages rather than offering substantial amounts of the data about the tests. Our focus group work, however, led us to believe we needed to present the key data. We found that if we could get people to consider the USPSTF recommendations, they wanted to know the data were available on which the recommendations were based, even if it was hard to understand. For the USPSTF mammography recommendation, where patients are encouraged to make a personal, informed decision rather than a specific choice, we are unclear what the appropriate next step should be for those who, understanding the issues, find themselves uncertain about what to do. Providing additional resources may help some patients, but finding resources for unbiased, balanced, and sufficiently complete information is problematic. Choosing what information to present, the order and style of presentation, and the amount of detail is an editorial choice that reflects the views of the developers. The more controversial the decision, the more difficult and important such choices will be. Carefully trained navigators might be able to help uncertain patients make a choice without injecting bias, but sustainable funding for such efforts outside a few special cases seems unlikely. Our findings also highlight that better informed patients may be less likely to want to share decision making with their clinicians.

Of note, most women expressed a preference for biennial rather than annual screening after seeing both interventions. If such a decision were durable and acted upon, it would substantially reduce the harms and costs of mammography with a minimal decrease in benefit. ${ }^{45}$

We found similarly substantial reductions in decisional conflict with our narrated, persuasive video interventions and the print decision-aid interventions, whereas only our video interventions had any effect on preferences. For mammography, we had hypothesized that a greater understanding of the issues might lead to greater decisional conflict, but we did not observe this outcome. Our findings should lead to careful thought about the role of decisional conflict in assessing overall decisional quality, because they suggest that a reduction in decisional conflict may be more reflective of going through the process of making or confirming a previous decision than of how well information was really understood and utilized.

Our study has a number of limitations. First, we measured a short-term change in attitudes, but we do not know whether this change will translate into action. Second, the print interventions we used for compari- 
son cannot be assumed to be representative of all print decision aids intended to inform but not designed to be persuasive interventions. We believed it was important to present for comparison nonproprietary decision aids that did not conflict with the evidence summaries produced for the USPSTF. Our video interventions differed in many ways from the paper decision aids used for comparison besides their persuasive aims. The paper PSA decision aid encouraged making a choice based on personal values and consulting one's physician, so any induced change would be expected to be smaller. Our narrated video slide shows with a story line were more engaging than the print presentations. Our video interventions ran 13 to 23 minutes, substantially longer than participants spent with the print decision aids and provided more detailed information, because our formative work indicated patients wanted to see the evidence when considering the counterintuitive USPSTF recommendations. It is possible that narrated presentations of similar length and detail but not designed to encourage viewers to trust and accept a specific recommendation would have had similar effects. Based on our experiences in phase 1 of this project, we think this is unlikely. Third, we chose to use the low-literacy version of the Decisional Conflict Scale, because we were expecting many participants to have limited literacy. The article describing the low-literacy version of the Decisional Conflict Scale raised some questions about distinctness and validity of some subscales, however, so our findings could be affected by specific characteristics of the low-literacy Decisional Conflict Scale. Finally, we tested our interventions with small, convenience samples of men and women in one city in central Massachusetts. Generalizability of our findings to other populations needs to be evaluated in future studies.

Given our results, we believe that findings from our prior qualitative work, along with guidance from behavioral science and marketing research, led to the success of our video interventions. If our video intervention findings are replicated in other populations, they could serve as a template for the development of persuasive interventions when targeting other controversial recommendations and low-value procedures. We offer the following points when developing such interventions:

1. Begin by asking people to think about the key questions without directly confronting their existing beliefs to set the stage for reconsideration while minimizing the risk of a defensive response.

2. Follow with describing harms and making explicit that benefits are smaller than most believe.

3. Offer difficult information more than once, with increasing detail, to allow viewers to grasp the overall message before they try to understand the finer details.
4. Portray a trusted professional as the source of information to encourage narrative engagement and evoke credibility.

A key question is whether interventions such as ours will lead to changes in behavior. An important next step is testing such interventions in pragmatic clinical trials to evaluate them in clinical practice.

We are aware that a persuasive approach is likely to arouse controversy, because persuasion is sometimes used to convince people to make choices not to their advantage. The reality, however, is that persuasive messages have been widely disseminated for many years, with the result that few patients are starting from a neutral position. We believe that it is important to accept that, in the face of advocacy messages and the power of anecdotes, persuasive counter-messaging may be both needed and warranted to convince consumers to be receptive to evidence and evidence-based recommendations that may run counter to existing beliefs and help them make more evidence-based choices.

To read or post commentaries in response to this article, see it online at http://www.annfammed.org/content/15/1/48.

Key words: early detection of cancer; cancer screening; clinical decision making; mammography; prostate cancer; persuasive interventions

Submitted March 17, 2016; submitted, revised, July 19, 2016; accepted August 9, 2016.

Funding support: Research reported in this article was funded through a Patient-Centered Outcomes Research Institute (PCORI) Award (1IP2PI000633).

Disclaimer: The views, statements, and opinions presented in this paper are solely the responsibility of the authors and do not necessarily represent the views of the Patient-Centered Outcomes Research Institute (PCORI), its Board of Governors, or Methodology Committee.

Previous presentations: This study was presented in part at the North American Primary Care Research Group Annual Meeting, November 9-13, 2013, Ottawa, Ontario, Canada; the North American Primary Care Research Group Annual Meeting, November 21-25, 2014, New York, New York; and the 2015 AcademyHealth Annual Meeting, June 14-16, 2015, Minneapolis, Minnesota.

Acknowledgments: We are grateful to the Edward M. Kennedy Community Health Center in Worcester, Massachusetts, for assistance in recruiting study participants. We are also grateful for the contributions of Joanne Calista, MS, LICSW of Central Massachusetts AHEC (now Center for Health Impact) for her contributions to development and conduct of this project.

Supplementary materials: Available at http://www.AnnFamMed. org/content/15/1/48/suppl/DC1/.

\section{References}

1. Fagerlin A, Wang C, Ubel PA. Reducing the influence of anecdotal reasoning on peoples health care decisions: is a picture worth a thousand statistics? Med Decis Making. 2005;25(4):398-405. 
2. Loewenstein GF, Weber EU, Hsee CK, Welch N. Risk as feelings. Psychol Bull. 2001;127(2):267-286.

3. Ariely D. Predictably Irrational: The Hidden Forces That Shape Our Decisions. New York, NY: Harper; 2008.

4. Kahneman D. Thinking, Fast and Slow. New York, NY: Farrar, Straus and Giroux; 2011.

5. Kahneman D, Slovic P, Tversky A. Judgment Under Uncertainty: Heuristics and Biases. New York, NY: Cambridge University Press; 1982.

6. Kahneman D, Tversky A. Prospect theory: An analysis of decisions under risk. Econometrica. 1979;47(2):263-291.

7. Kahneman D, Tversky A. Choices, Values, and Frames. Cambridge, UK: Russell Sage Foundation; Cambridge University Press; 2000.

8. Schwartz B. The Paradox of Choice: Why More is Less. New York: New York, NY: Ecco; 2004.

9. Fagerlin A, Zikmund-Fisher BJ, Ubel PA. If I'm better than average, then I'm ok?: comparative information influences beliefs about risk and benefits. Patient Educ Couns. 2007;69(1-3):140-144.

10. Fagerlin A, Zikmund-Fisher BJ, Ubel PA. Helping patients decide: ten steps to better risk communication. J Natl Cancer Inst. 2011; 103(19):1436-1443.

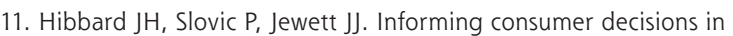
health care: implications from decision-making research. Milbank $Q$. 1997;75(3):395-414.

12. Peters E, Dieckmann N, Dixon A, Hibbard JH, Mertz CK. Less is more in presenting quality information to consumers. Med Care Res Rev. 2007;64(2):169-190.

13. Zikmund-Fisher BJ, Angott AM, Ubel PA. The benefits of discussing adjuvant therapies one at a time instead of all at once. Breast Cancer Res Treat. 2011;129(1):79-87.

14. Zikmund-Fisher BJ, Fagerlin A, Ubel PA. A demonstration of less can be more in risk graphics. Med Decis Making. 2010;30(6):661-671.

15. Payne JW, Bettman JR, Johnson EJ. The Adaptive Decision Maker. New York, NY: Cambridge University Press; 1993.

16. Tversky A, Sattah S, Slovic P. Contingent weighting in judgement and choice. Psychol Rev. 1988;95(3):371-384.

17. Charles C, Gafni A, Whelan T. Shared decision-making in the medical encounter: what does it mean? (or it takes at least two to tango). Soc Sci Med. 1997;44(5):681-692.

18. Slovic P. The construction of preference. American Psychologist. 1995;50(5):364-371.

19. Stacey $D$, Légaré $F$, Col NF, et al. Decision aids for people facing health treatment or screening decisions. Cochrane Database Syst Rev. 2014;1(1):CD001431.

20. Schwartz LM, Woloshin S, Fowler FJ Jr, Welch HG. Enthusiasm for cancer screening in the United States. JAMA. 2004;291(1):71-78.

21. Mazor KM, Calvi J, Cowan R, et al. Media messages about cancer: what do people understand? J Health Commun. 2010;15(Suppl 2): 126-145.

22. Sutkowi-Hemstreet A, Vu M, Harris R, Brewer NT, Dolor RJ, Sheridan SL. Adult patients perspectives on the benefits and harms of overused screening tests: a qualitative study. J Gen Intern Med. 2015;30(11):1618-1626.

23. Nekhlyudov L, Braddock CH III. An approach to enhance communication about screening mammography in primary care. Jomens Health (Larchmt). 2009;18(9):1403-1412.

24. US Preventive Services Task Force. Screening for breast cancer: U.S Preventive Services Task Force recommendation statement [published corrections appear in Ann Intern Med. 2010;152(3):199-200, Ann Intern Med. 2010;152(10):688]. Ann Intern Med. 2009;151(10): 716-726,W-236.

25. Siu AL. Screening for Breast Cancer: U.S. Preventive Services Task Force Recommendation Statement. Ann Intern Med. 2016; 164(4): 279-296.
26. Moyer VA. Screening for prostate cancer: U.S. Preventive Services Task Force recommendation statement. Ann Intern Med. 2012;157(2): 120-134.

27. Hofmann B, Lysdahl KB. Moral principles and medical practice: the role of patient autonomy in the extensive use of radiological services. J Med Ethics. 2008;34(6):446-449.

28. Holden DJ, Jonas DE, Porterfield DS, Reuland D, Harris R. Systematic review: enhancing the use and quality of colorectal cancer screening. Ann Intern Med. 2010;152(10):668-676.

29. Schiff GD, Wisniewski M, Bult J, Parada JP, Aggarwal H, Schwartz DN. Improving inpatient antibiotic prescribing: insights from participation in a national collaborative. Jt Comm J Qual Improv. 2001; 27(8):387-402.

30. Drazer MW, Huo D, Schonberg MA, Razmaria A, Eggener SE. Population-based patterns and predictors of prostate-specific antigen screening among older men in the United States. J Clin Oncol. 2011;29(13):1736-1743.

31. Li J, Zhao G, Pollack LA, Smith JL, Joseph DA. Use of the prostatespecific antigen test among men aged 75 years or older in the United States: 2006 Behavioral Risk Factor Surveillance System. Prev Chronic Dis. 2010;7(4):A84.

32. Emanuel EJ, Young-Xu Y, Levinsky NG, Gazelle G, Saynina O, Ash AS. Chemotherapy use among Medicare beneficiaries at the end of life. Ann Intern Med. 2003;138(8):639-643.

33. Saito AM, Landrum MB, Neville BA, Ayanian JZ, Earle CC. The effect on survival of continuing chemotherapy to near death. $B M C$ Palliat Care. 2011;10:14.

34. Bekker HL. Decision aids and uptake of screening. BMJ. 2010;341: c5407.

35. Swindell JS, McGuire AL, Halpern SD. Beneficent persuasion: techniques and ethical guidelines to improve patients decisions. Ann Fam Med. 2010;8(3):260-264.

36. Swindell JS, McGuire AL, Halpern SD. Shaping patients decisions. Chest. 2011;139(2):424-429.

37. Massachusetts Department of Public Health. Prostate cancer screening fact sheet. http://www.mass.gov/eohhs/docs/dph/cancer/prostate/psa-be-smart.pdf. Accessed Nov 30, 2016.

38. Massachusetts Department of Public Health. Should you get the PSA test? In-office decision aid. http://www.mass.gov/eohhs/docs/ dph/cancer/prostate/psa-should-you.pdf. Accessed Nov 30, 2016.

39. Summaries for patients. Screening mammography in women age 40 to 49 years. Ann Intern Med. 2007;146(7):I20.

40. Harris PA, Taylor R, Thielke R, Payne J, Gonzalez N, Conde JG. Research electronic data capture (REDCap) - a metadata-driven methodology and workflow process for providing translational research informatics support. J Biomed Inform. 2009;42(2):377-381.

41. Linder SK, Swank PR, Vernon SW, Mullen PD, Morgan RO, Volk RJ. Validity of a low literacy version of the Decisional Conflict Scale. Patient Educ Couns. 2011;85(3):521-524.

42. OConnor AM. Validation of a decisional conflict scale. Med Decis Making. 1995;15(1):25-30.

43. Sheridan SL, Sutkowi-Hemstreet A, Barclay C, et al. A comparative effectiveness trial of alternate formats for presenting benefits and harms information for low-value screening services: a randomized clinical trial [published correction appears in JAMA Intern Med. 2016;176(2):284]. JAMA Intern Med. 2016;176(1):31-41.

44. Eden KB, Scariati $P$, Klein $K$, et al. Mammography decision aid reduces decisional conflict for women in their forties considering screening. J Womens Health (Larchmt). 2015;24(12):1013-1020.

45. Mandelblatt JS, Stout NK, Schechter CB, et al. Collaborative modeling of the benefits and harms associated with different U.S. breast cancer screening strategies. Ann Intern Med. 2016;164(4):215-225. 